\title{
Communications in Hybrid Arrangements: Case of Australian Construction Project Teams
}

\author{
M. Reza Hosseini ${ }^{1}$, Edmundas Kazimieras Zavadskas ${ }^{2}$, Bo Xia ${ }^{3}$, Nicholas Chileshe ${ }^{4}$, Anthony \\ Mills ${ }^{5}$ \\ ${ }^{1,5}$ Deakin University \\ Locked Bag 20001, Geelong, Victoria, Australia \\ E-mail.Reza.Hosseini@deakin.edu.au,Anthony.Mills@deakin.edu.au
}

${ }^{2}$ Institute of Internet and Intelligent Technologies

Vilnius Gediminas Technical University

Sauletekio av. 11, 10223, Vilnius, Lithuania

E-mail.edmundas.zavadskas@vgtu.ltpaul.xia@qut.edu.au

${ }^{3}$ Queensland University of Technology

GPO Box 2434, Brisbane, QLD 4001, Australia

E-mail.paul.xia@qut.edu.au

${ }^{4}$ University of South Australia

GPO Box 2471, Adelaide, SA 5001, Australia

E-mail.Nicholas.Chileshe@unisa.edu.au

cross $^{r e f} \underline{\text { http://dx.doi.org/10.5755/j01.ee.28.3.13791 }}$

Hybrid team arrangements or partially virtual teams are increasingly being utilised as the structure for construction project teams. However, little research has been conducted on the quality of the communications of these teams. To address the identified research gap, this study adopted a sequential mixed-methods approach. In the first phase, a multidisciplinary literature review identified 7 major indicators of the quality of communications. After conducting 17 interviews with construction experts, the study customised these indicators for the construction context, in form of a list that comprised 12 indicators. Based on the indicators in this list, a questionnaire survey was then designed to elicit construction practitioners' perceptions on changes in the quality of communications in hybrid team arrangements compared to teams that were fully collocated. Data from the 285 completed questionnaires in Australia then underwent confirmatory factor analysis (CFA). In the findings, the move to hybrid working arrangements was shown to create changes in 10 of the 12 indicators. The identified list of indicators is a significant contribution to the literature, and provides construction practitioners with guidance in assessing the quality of communications in these teams. The findings also shed light on the primary changes in the quality of communications resulting from the increasing use of hybrid team arrangements.

Keywords: Communications, Quality, Hybrid Teams, Construction Project Teams, Australia.

\section{Introduction}

In today's construction industry, hybrid teams (HTs) are emerging as a novel organisational structure in projects (Chen \& Messner, 2010; Hosseini, Chileshe, Zuo, \& Baroudi, 2015). Construction organisations are now dealing with teams with“... some face-to-face interaction along with a healthy dose of virtual interaction" (Schroeder, 2013, p. 1). In the literature, these are known as "hybrid teams" (Hosseini, Zuo, Chileshe, \& Baroudi, 2015; Watson-Manheim, Chudoba, \& Crowston, 2012). According to Chinowsky and Rojas (2003), in the near future, organisational structures will be formed with hybrid teams (HTs) as a central component. Iorio and Taylor (2014) added their view that business will be conducted in this way by construction organisations. This insight was reaffirmed by Becerik-Gerber, $\mathrm{Ku}$ and Jazizadeh (2012, p. 234) who stated that “... today's construction projects require project teams that are geographically dispersed" adding that these teams will need to "work ... across multiple time zones and numerous organizational boundaries in a variety of cultures". Consequently, an area in which a comprehensive insight was needed through further research was how hybrid construction team members interact (Bosch-Sijtsema \& Henriksson, 2014; Dossick et al., 2015).

Within the context of construction project teams, the quality of communications between team members is of utmost importance (Ahuja, Yang, \& Shankar, 2010; Dossick et al., 2015). The quality of communications has far-reaching impacts on major aspects of team effectiveness which, accordingly, are translated into outcomes in construction projects (Dainty, Moore, \& Murray, 2005; Martin, Lewis, \& Fifi, 2014). As contended by Zavadskas, Turskis and Tamošaitiene (2010), in order to succeed, construction team members place a significant amount of reliance on the quality of the information and data that they exchange. In essence, establishing high quality communications is a precursor for the design of construction teams, as stated by Martin et al. (2014). Thus, it is crucial to understand how information technology impacts on the quality of communications in these teams (Dainty et al., 2005; Xie, Wu, Luo, \& Hu, 2010). 
Conversely, even though Xie et al. (2010) considered the area "inexhaustible", there is a paucity of research on the quality of communications between members of construction teams. The studies that are available appear to have devoted insufficient attention to the aspects of communications in construction projects that are unique and idiosyncratic, as stated by Westin and Sein (2014). In addition, Weber and Kim (2015), in reviewing the literature, found that empirical research was conspicuously absent on how HTs, in comparison to collocated teams, affect the quality of communications. The present study has been motivated by the need and importance of bridging this gap in the existing literature. Consequently, the primary objectives of this study are: (1) to identify and define indicators that can be used to evaluate the quality of communications between construction project team members; and (2) to map which indicators are more likely to be affected due to the particular idiosyncrasies of hybrid team working arrangements in construction project teams.

\section{Research Background}

\section{Communications}

Various definitions have been proposed for the term 'communication' with Cheng, Li, Love and Irani (2001, p. 63) identifying "the transmission of resources (e.g. information and other meanings including ideas, knowledge, specific skills and technology)" with this needing to be "from one party to another" and by means of "the use of shared symbols and media". Communication could be defined simply as "... sharing relevant information between project participants" (Ceric, 2014, p. 829). Recent definitions of communication have emphasised the inclusion of information/ideas exchange, as pointed out by Tourish and Hargie (2009). The prevalence of high quality communications is of cardinal importance and is a prerequisite for the success of an organisation (Hartley \& Bruckham, 2000; Mithas, Ramasubbu, \& Sambamurthy, 2011). In terms of construction projects, the quality of communications plays a pivotal role in enhancing the effectiveness of construction teams (Bosch-Sijtsema \& Henriksson, 2014; Xie et al., 2010), with this, accordingly, resulting in better project performance, as observed by Cheung, Yiu and Lam (2013). As articulated by Thomas, Tucker and Kelly (1998) and Senaratne and Ruwanpura (2015), high quality communications are central to the successful delivery of projects in the construction industry, as described below.

\section{Communications Quality}

As pointed out by Mohr and Sohi (1996), researchers have largely deployed two overarching indicators for evaluating the quality of communications. These indicators: (1) consider the nature of the flows of communications (e.g. the frequency of communications) between the involved parties; and (2) focus on the involved parties' judgments regarding the quality of communications, for instance, evaluating the helpfulness of communications. According to Mohr and Sohi (1996), communications quality only covers those aspects of communications (e.g. accuracy, completeness, timeliness, credibility and adequacy) that can be assessed from the perspective of the judgments of the involved parties. From another perspective, Aubert, Hooper and Schnepel (2013) classified the main attributes of communications into form (e.g. timeliness) and content (e.g. accuracy), stating that both categories are equally important. These authors added that when evaluating the quality of communications, form and content should be incorporated. For the construction industry, according to Martin et al. (2014), communications are comprised of the difficulty (a stable and steady component) and the quality (a dynamic component) of the transfer of information.

Despite the quality of communications' cardinal importance for the construction industry, only a few studies, such as the work of Xie et al. (2010), have mentioned indicators that can be used in this assessment. Consequently, it was necessary to extract the indicators defined and illustrated in Table 1 from previous studies that had been conducted from a multidisciplinary perspective.

As inferred from Table 1, investigators in the construction industry have utilised an incomplete battery of indicators to evaluate the quality of communications. Moreover, construction studies on the quality of communications in hybrid teams have largely treated communications merely as a measure for data transfer, as postulated by Ramalingam, Lobo, Mahalingam and Whyte (2014). Thus, several dimensions of the quality of communications have remained unnoticed in the construction literature.

\section{Communications Quality in Hybrid Teams}

Contemporary construction organisations deploy very few fully collocated teams as teams today almost entirely operate in semi-virtual arrangements (Hosseini, Chileshe et al., 2015). Collocated teams are also increasingly depending on technology for the exchange of communications and data between team members (Gabrielaitis \& Bausys, 2015; Ramalingam et al., 2014). As explained by Bosch-Sijtsema and Henriksson (2014), this provides the rationale for why construction teams now operate more and more under hybrid arrangements. In the construction industry context, it is paramount that HTs maintain the quality of communications: poor quality communications seriously reduce the effectiveness of HTs' performance (Ramalingam et al., 2014).

The literature review revealed the high level of research activity investigating the extent to which the move to hybrid team working affects communications quality. However, Verburg, Bosch-Sijtsema and Vartiainen (2013) asserted that confusing and even contradictory views are emerging from this research. Investigators, such as Moum (2010), have put forward the idea that higher dependency on computer-aided media in hybrid teams enhances the quality of communications by promoting collaboration in construction teams. Likewise, other investigators have found that the exchange of knowledge and information is assisted by working in a hybrid arrangement (Griffith, Sawyer \& Neale, 2003). 
Indicators and their Definitions

\begin{tabular}{|c|c|c|}
\hline Indicator & Definition & References \\
\hline Accuracy* & $\begin{array}{l}\text { The data are correctly transferred without bias, any distortion or } \\
\text { withholding of information. }\end{array}$ & $\begin{array}{c}\text { (Aubert et al., 2013; Kahn, Strong, \& Wang, } \\
\text { 2002; Miller, 2005; Thomas et al., 1998; Xie et } \\
\text { al., 2010) }\end{array}$ \\
\hline Completeness* & $\begin{array}{l}\text { All the essential data are available and no required information is } \\
\text { missing. }\end{array}$ & $\begin{array}{l}\text { (Aubert et al., 2013; Kahn et al., 2002; Thomas } \\
\text { et al., 1998; Xu, Nord, Nord, \& Lin, 2003) }\end{array}$ \\
\hline Reliability & The receiver regards information as reliable. & $\begin{array}{c}\text { (Aubert } \text { et al., 2013; Kahn et al., 2002; Miller, } \\
\text { 2005) }\end{array}$ \\
\hline Understandability* & The audience easily comprehend the provided data and information. & $\begin{array}{l}\text { (Aubert et al., 2013; Kahn et al., 2002; Miller, } \\
\text { 2005; Thomas et al., 1998; Xie et al., 2010) }\end{array}$ \\
\hline Bidirectionality & $\begin{array}{l}\text { Feedback, clarifications and verifications are easily obtainable from the } \\
\text { involved parties. }\end{array}$ & (Aubert et al., 2013; Mohr \& Sohi, 1996) \\
\hline Timeliness* & The information is provided on time (not earlier and with no delay). & $\begin{array}{l}\text { (Aubert et al., 2013; Kahn et al., 2002; Miller, } \\
\text { 2005; Thomas et al., 1998; Xie et al., 2010) }\end{array}$ \\
\hline Frequency & This notes how often involved parties contact each other. & $\begin{array}{l}\text { (Ellwart, Happ, Gurtner, \& Rack, 2015; Mohr \& } \\
\text { Sohi, 1996) }\end{array}$ \\
\hline
\end{tabular}

In the same vein, Bosch-Sijtsema and Henriksson (2014) suggested that, by combining and leveraging the different styles of HT interactions that commonly occur, the project teams' embedded and distributed knowledge could be better managed and communicated. Conversely, den Otter and Emmitt (2007) and Wang, Love, Kim and Wang (2014) highlighted the necessity of holding face-to-face meetings to maintain the quality of communications, thus indirectly referring to the diminished quality of communications in hybrid arrangements. Likewise, Ellwart et al. (2015) identified that working in hybrid teams results in an excess amount of low quality information being exchanged, with this identified as "information overload", necessitating that hybrid team members address this issue by changing their communications behaviour.

In light of the confusion in the findings in the extant literature, further research is warranted on how hybrid team working impacts on the identified indicators of the quality of communications. To address this need, the present study deployed the research methods described below.

\section{Research Methods}

A sequential mixed-methods research approach has been employed in this study (see Figure 1). This comprised a qualitative phase which was followed by a quantitative phase with this termed a "sequential exploratory design" (Creswell, Plano Clark, Gutmann \& Hanson, 2003). With the identified absence of indicators that could be used to evaluate the quality of communications in construction project teams, the qualitative phase of the present study was used to identify and validate indicators. The reason is that qualitative research tends to focus more on concept building and concept generation, whereas quantitative research is more concerned with testing and/or verification (Punch, 2005). Furthermore, the study's objectives dictated a focus on construction project teams as the designated context. This required starting with a context-oriented approach, with the qualitative approach effective in studying specific contexts and settings, as asserted by Creswell (2009). In other words, qualitative research is "sensitive to context and process, to lived experience and to local grounded-ness" Punch (2005, p. 238).

The quantitative phase then investigated how communications quality changed as teams shifted to hybrid arrangements, with this measured by the defined indicators. A thorough exploration could thus be undertaken of the study's topic: as asserted by Creswell et al. (2003), the results of quantitative studies, if using large samples, can be inferred to a population. In essence, as postulated by Hyde (2000, p. $82)$, "... the findings of qualitative enquiry remain tentative as long as they are untested".

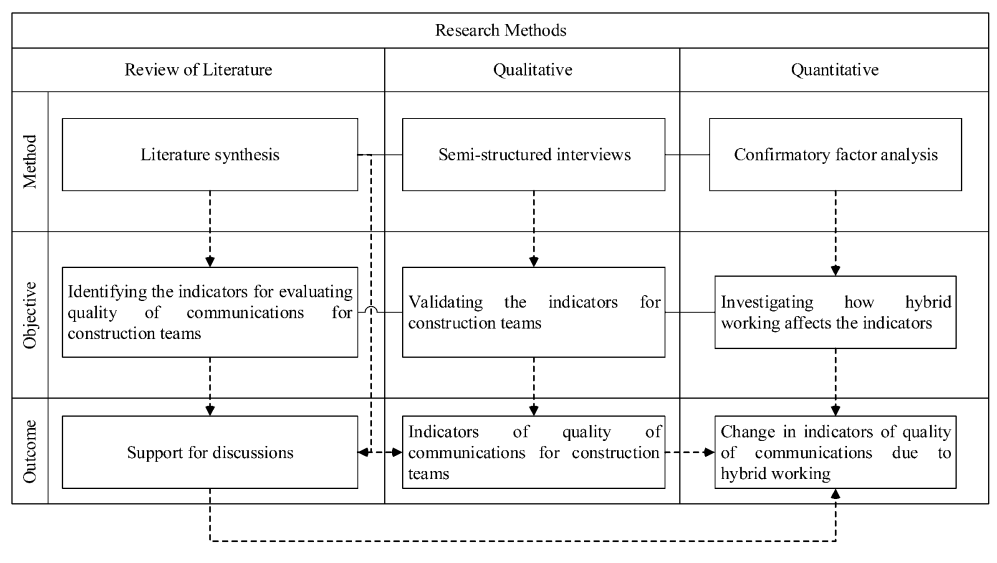

Figure 1. Research Methods and Process 


\section{Qualitative Approach}

As illustrated in Figure 1, the study commenced with a qualitative phase to refine, supplement and customise the indicators found in the literature. Interviewees were asked for their insights on the indicators identified in the literature review. The interviews were semi-structured in format: interviewees were asked for their views on the list of indicators with suggestions for additional items welcome. Interviewees were sought who had sufficient HT experience in construction projects. To identify potential interviewees, the websites of leading companies were used as well as contacting groups dedicated to virtual construction, through professional networks on social media (e.g. LinkedIn). In all, 64 invitations were sent which resulted in 17 interviewees agreeing to participate. All the interviewees were from Australia and deemed to be adequately knowledgeable on the topic under investigation, as illustrated in Table 2. After obtaining official consent from all interviewees, interviews of durations ranging from 40 to 58 minutes, were recorded.

Table 2

Interviewees' Profiles

\begin{tabular}{cclc}
\hline No. & $\begin{array}{c}\text { Interviewees' } \\
\text { IDs }\end{array}$ & Occupation & Experience (years) \\
\hline 1 & $\mathrm{~A}$ & Designer & 17 \\
2 & $\mathrm{~B}$ & Government & 21 \\
3 & $\mathrm{C}$ & Project manager & 11 \\
4 & $\mathrm{D}$ & Designer & 9 \\
5 & $\mathrm{E}$ & Contractor & 9 \\
6 & $\mathrm{~F}$ & Project manager & 18 \\
7 & $\mathrm{G}$ & Designer & 9 \\
8 & $\mathrm{H}$ & Contractor & 8 \\
9 & $\mathrm{I}$ & Drafter & 10 \\
10 & $\mathrm{~J}$ & Researcher & 10 \\
11 & $\mathrm{~K}$ & Drafter & 8.5 \\
12 & $\mathrm{~L}$ & Designer & 11 \\
13 & $\mathrm{M}$ & Drafter & 9 \\
14 & $\mathrm{~N}$ & Government & 10 \\
15 & $\mathrm{O}$ & Designer & 8 \\
16 & $\mathrm{P}$ & Project manager & 15 \\
17 & $\mathrm{Q}$ & Drafter & 8 \\
\hline
\end{tabular}

\section{Quantitative Approach}

In the present study's quantitative phase, the questionnaire used in the survey was made up of two sections. The first section sought answers to six questions on respondents' demographic attributes. In the second section, respondents were asked to use 7-point Likert scales (ranging from 1 'very strongly disagree' to 7 'very strongly agree') to rate the extent to which they agreed with the statements. Respondents indicated how much they thought each indicator of the quality of communications might be affected through a shift in team working from being collocated towards being purely virtual (thus resembling the HT working environment). The survey's target population comprised those working in construction who had experience in hybrid teams and included project managers, architects, design consultants, engineers, facility managers and contractors in
Australia. With this being an online survey, the cover letter provided the link to the questionnaire as well as conveying the survey invitation. Email was used to send the letter to 728 architectural firms, 852 design firms, 1308 contractors and 795 construction management enterprises. In all, 285 duly completed questionnaires were received, a response rate of 8 $\%$. The quite low response rate could be justified by the fact that not all construction practitioners were experienced in hybrid team working.

Byrne (2001) emphasised the great potential of structural equation modelling (SEM) which could be employed to test theories that involved relationships between latent variables and constructs with observed variables. In construction research, SEM has been extensively used to characterise the associations between unobserved and observed variables (Ke, Cui, Govindan, \& Zavadskas, 2015). As described by Kline (2011), SEM is an umbrella method that encompasses a family of techniques including confirmatory factor analysis (CFA). Researchers have used CFA for investigating the nature of relationships between constructs and items that are regarded as their indicators (Brown, 2006; Byrne, 2001). In other words, a CFA model with a good fit identifies which of the indicators best describes that particular construct. Schreiber, Nora, Stage, Barlow and King (2006) added that researchers are assisted by CFA models with a good fit when investigating if any significant relationships exist between the constructs of the model The CFA model results show the underlying nature of relationships between the constructs and their indicators. According to Harrington (2009, p. 12) “... CFA focuses on the relationships between the indicators and latent variables". Therefore, the present study selected CFA as the method to analyse the associations of the indicators of the quality of communications, with the quality of communications as the underlying factor (i.e. the latent variable).

\section{Results \\ Qualitative}

Using software packages, such as NVivo, in qualitative studies can enhance the rigour and accuracy of data analysis, provide deeper insight and speed up the data analysis process (Lewins \& Silver, 2007). As argued by Bazeley (2013), using NVivo provides much more flexibility in coding interview transcripts than can be achieved by manual data analysis on paper. Therefore, NVivo 10 was deployed for the coding of the interview transcripts. In the present study, coding began by preparing a list of "a priori codes", as described by Bazeley (2013, p. 170). Hence, a list of researcher(s)-generated codes was prepared based on synthesising the findings of the literature review, as illustrated in Table 1. Taking advantage of such a technique ensures that research questions and findings remain connected to the existing knowledge while creating fresh knowledge (Bazeley, 2013). In total, 11,976 words were coded based on the statements of interviewees regarding the indicators of the quality of communications for construction project teams.

Figure 2 illustrates the percentages of words coded for each indicator from the total of 11,976 coded words. In analysing the interviews, the number of words referring to 
one concept could be indicative of the relative level of importance of that concept. That is, the more important concepts are more frequently mentioned within interview transcripts (Bazeley, 2007). Considering the counts of words as a measure for assessing the level of support for concepts embedded in interview transcripts was supported by Onwuegbuzie, Dickinson, Leech and Zoran (2009, p. 9) who asserted that "... when contextualized, the use of counts can provide richer information than would be obtained by using qualitative data alone ..."

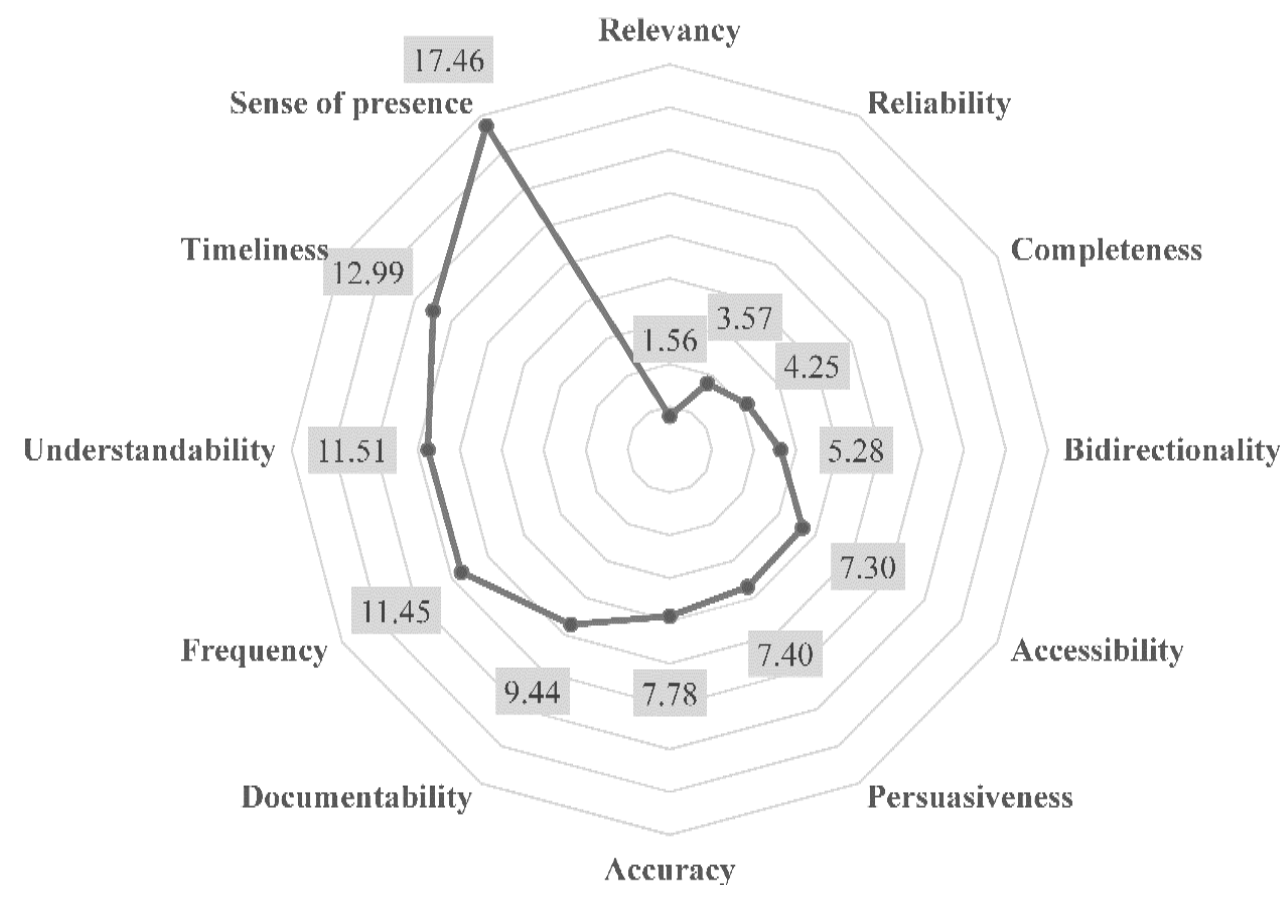

Figure 2. The 12 Indicators Identified Through the Qualitative Phase Note: Numbers illustrate the percentage of words coded for each indicator.

\section{Quantitative}

As suggested by Brown (2006), when investigating whether indicators are significantly associated with their underlying latent variable (i.e. construct), investigators can use CFA models with one latent variable and a minimum of four indicators. The present study deployed the CFA model shown in Figure 3 to investigate the relationships between the construct and its 12 indicators (i.e. the difference in the quality of communications).

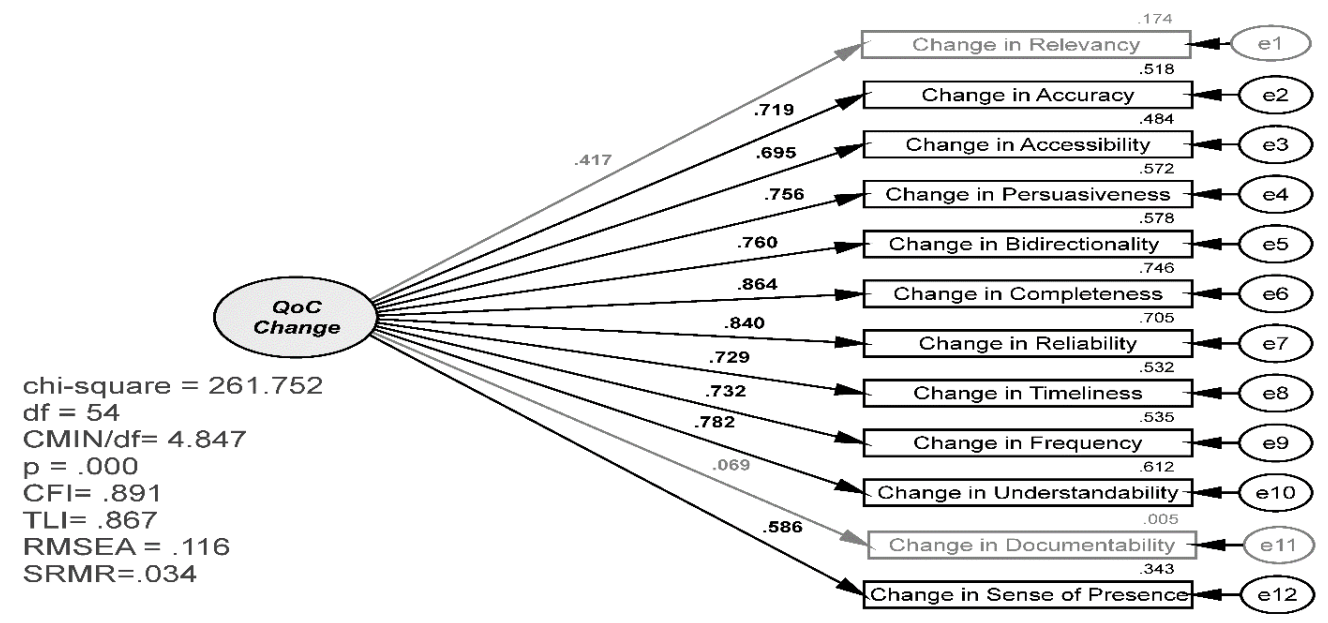

Figure 3. Basic Model to Evaluate Change in Quality of Communications

Note: $C F I=$ comparative fit index; $C M I N=$ chi-square value; $d f=$ degrees of freedom; $p=$ calculated probability; $Q o C=q u a l i t y$ of communications; $R M S E A=$ root mean square error of approximation; $S R M R=$ standardised root mean square residual; $T L I=T u c k e r-L e w i s$ index

This study used maximum likelihood (ML) to estimate the CFA model. According to Xiong, Skitmore and Xia (2015), maximum likelihood (ML) is the most common method used in the construction literature for performing
SEM: in addition, it is relatively robust to moderate violations of normality. IBM's SPSS Amos, widely known as AMOS, is a computer tool specifically constructed for implementing tests of data analysis and a hypothetical model based on SEM 
principles (Kline, 2011). As one of the most common SEM software packages, AMOS is able to deploy two core modules to conduct SEM investigations using AMOS graphics or AMOS thus making it one of the most userfriendly SEM packages (Blunch, 2013). IBM's SPSS Amos 22 was therefore used as the software package to implement the required analysis in the present study.

The analysis results for the basic model (see Figure 3) indicated that the current CFA model should be modified as it does not fit the data. According to Kline (2011), the key fit indices to be considered in CFA model evaluations should include model chi-square $\left(x^{2}\right)$; root mean square error of approximation (RMSEA); comparative fit index (CFI); and standardised root mean square residual (SRMR) statistics. The simultaneous use of all these items to evaluate the fit of the model provides adequate rationale for their use in assessing the goodness of fit of CFA models (Kline, 2011). A model with a fair fit to the sample data will have a CFI value greater than 0.9, a RMSEA value between 0.05 and 0.08 , and a SRMR value less than 0.08 (Xiong et al., 2015). In addition, to moderate the impact of sample size on chi-square results, $\frac{x^{2}}{d f}$ is a reliable measure, with a value lower than 3.0 regarded as an acceptable sign of model fit. As shown in Figure 3, except for a SRMR value of 0.06 which is less than 0.08 as recommended), all the other fit indices $\left(\frac{x^{2}}{d f}=4.87>3\right.$; $\mathrm{CFI}=.891<0.9$; RMSEA $=0.116>0.08$ ) showed unsatisfactory results.
To modify the model, any items with $R^{2}$ (i.e. squared multiple correlation) values less than 0.2 should be removed from the model as these values indicate large amounts of error (Hooper, Coughlan, \& Mullen, 2008). In the present study, the indicators of documentability and relevancy had $R^{2}$ values equal to 0.005 and 0.174 , respectively (as illustrated in light grey in Figure 3); thus, they were removed from the model. The implications is that relevancy (of communications) and documentability (of information) did not significantly differ between HTs and collocated teams. In other words, these two indicators do not reflect changes between the quality of communications in HTs and collocated teams. As indicated by Hooper et al. (2008), the defining of free covariance among measurement errors within-factors is an acceptable practice. As shown in Figure 4, this technique was used to revise the model by freeing the covariance between measurement errors.

The fit of the CFA models can assess the strength and size of the relationships between the constructs and indicators. To rank the indicators, as suggested by Brown (2006), the size of the correlation between each indicator in the model and its underlying construct shows the relative importance of the indicator in reflecting changes in the construct. Hence, the loadings of indicators, as illustrated in Table 3, were considered as the basis for assessing the level of change in each indicator.

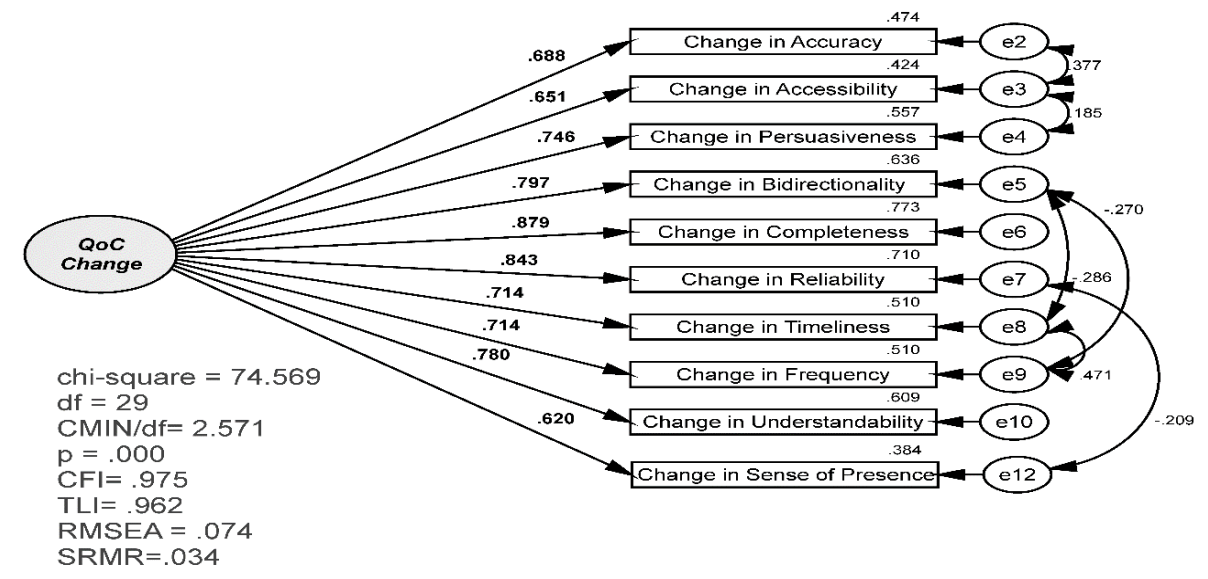

Figure 4. Modified Model to Evaluate Change in Quality of Communications

Relative Change of Indicators (Hybrid Teams Compared to Collocated Teams)

\begin{tabular}{|c|c|c|c|c|c|c|}
\hline \multirow{2}{*}{ Indicator } & \multicolumn{3}{|c|}{ Unstandardised Regression Weights } & \multirow{2}{*}{$\begin{array}{c}\text { Loadings } \\
\text { (correlations) }\end{array}$} & \multirow{2}{*}{$R^{2}$} & \multirow[t]{2}{*}{ Relative ranking } \\
\hline & Estimate & SE & CR & & & \\
\hline Completeness & 1.16 & 0.06 & 18.58 & 0.88 & 0.71 & 1 \\
\hline Reliability & 1.15 & 0.07 & 17.32 & 0.84 & 0.77 & 2 \\
\hline Bidirectionality & 1.07 & 0.07 & 15.85 & 0.80 & 0.51 & 3 \\
\hline Understandability & 0.97 & 0.06 & 15.44 & 0.78 & 0.42 & 4 \\
\hline Persuasiveness & 0.98 & 0.07 & 14.47 & 0.75 & 0.51 & 5 \\
\hline Timeliness & 1.02 & 0.08 & 13.52 & 0.71 & 0.64 & 6 \\
\hline Frequency & 0.89 & 0.07 & 13.52 & 0.71 & 0.56 & 7 \\
\hline Accuracy & 1.02 & 0.08 & 12.96 & 0.69 & 0.38 & 8 \\
\hline Accessibility & 0.96 & 0.08 & 12.04 & 0.65 & 0.61 & 9 \\
\hline Sense of presence & 0.79 & 0.07 & 11.25 & 0.62 & 0.47 & 10 \\
\hline
\end{tabular}

Note: $S E=$ standard error CR $=$ critical ratio 
In adopting the the critical ratio (CR) cut-off point of \pm 1.96 in order to identify significant relationships, as recommended by Brown (2006), all the indicators in Table 3 showed significant relationships, with $\mathrm{CR}$ values ranging from 11.25 to 18.58 . According to Brown (2006), if the value of the loading is greater than 0.4, this signifies that an indicator is a reasonable and salient measure for the underlying construct. As can be seen in Table 3, all the indicators are regarded as reasonable measures for changes in the quality of communications in hybrid construction project teams.

\section{Discussion}

\section{Indicators of quality of communications in construction teams}

The outcome of the qualitative analysis (as illustrated in Figure 2) comprises the finalisation of the twelve (12) main indicators, with these then used to evaluate the quality of communications. As can be seen, the literature review identified seven of the indicators (see Table 1), namely, accuracy, completeness, reliability, understandability, bidirectionality, timeliness and frequency, which the interviewees then verified. Five new indicators (i.e. sense of presence, documentability, persuasiveness, accessibility and relevancy) were added by the interviewees, As a result, the analysis of the interviews corroborated the indicators identified in the literature. However, as illustrated in Figure 2, the indicators sense of presence and documentability were relatively more important for construction practitioners in comparison to indicators identified by previous studies. Interviewees stated that indicators such as relevancy were not of central importance (see Figure 2). However, as they had been expressed by interviewees and in order to provide a comprehensive collection of indicators, they were added to the list.

\section{Sense of presence}

A sense of presence refers to the dimension of communications that enables the involved parties to “... understand the intentions and activities with a high level of awareness and presence as if they were working in the same room" (Wang et al., 2014, p. 314). As emphasised by the interviewees, irrespective of the working arrangement, when interacting with each other, team members should have a sense of presence in order to maintain high quality communications. According to den Otter and Emmitt (2007) and the media richness theory, a sense of presence is a necessary element of high quality communications.

"In construction you should always refer to some documents during communications including handouts, drawings, specifications, you should have tangible stuff to touch and sketch and draw" (Interviewee H).

This view was in close agreement with Wang et al. (2014) who stated that, in order for members of construction teams to have high quality communications, they should experience not only social capital but also interpersonal interactions that felt natural. Thus, sense of presence was added to the list of indicators.

\section{Documentability}

According to Gopsill, McAlpine and Hicks (2013), documenting communications in design teams will result in saving huge amounts of time through creating a knowledge base for reuse and prevention of rework. However, in the present study, interviewees looked at the potential documentability of communications through the lens of the lack of trust in hybrid construction project teams. Due to the reported lack of trust between construction project team members, it was indicated by interviewees that the documentability of the information exchanged is an aspect of high quality communications for these teams. In agreement with Rivard (2000), it was felt that the documentation of communications reduced the mistakes and sped up the completion of tasks in construction projects.

"You need back-up and document communications in the construction industry as it gives you negotiation power" (Interviewee D).

\section{Persuasiveness}

Whenever people communicate with other people in order to convince them that an idea or action has value, this involves persuasiveness (Vladutescu, 2014). Interviewees generally felt that elements of persuasion and conviction were needed in communications in construction project teams. For example, the sender of information may need, and should have the ability, to convince the receiver about a certain aspect of design or the required engineering calculations. This could be an important feature of communications in construction project teams as reaching a consensus on different matters within the project is needed by team members (den Otter \& Emmitt, 2007).

"A lot of it comes to helping understand why some decisions are made so [the] best communications [are] where the parties not only communicate the outcome or resolution to a problem but also could explain how that outcome [was] achieved and that explanation leads to pure understanding" (Interviewee N).

\section{Accessibility}

Interviewees were in agreement that, due to the nature of their tasks, construction team members frequently need to urgently communicate with their fellow team members to resolve project issues. Accessibility, as an element of communications, represents the speed with which communications and the exchange of information occur and whether they are easily possible (Kahn et al., 2002). Information is regarded as accessible when team members have access to the information to meet their needs and complete their tasks (Boritz, 2005). In light of the complicated nature and requirements of the tasks assigned to them, construction project teams consider accessibility to be an essential element of communications (Westin \& Sein, 2014)

\section{Relevancy}

As defined by Kahn et al. (2002), relevancy of communications is a measure that represents the extent to which the exchanged information is helpful for the receiver and applicable for the required task. As an outcome of the 
analysis, the relevancy of communications was considered of utmost importance in construction project teams and was consequently added to the list of indicators.

"The information should exactly answer the right question asked. And I stress that information should meet the clarity requirements" (Interviewee $\mathbf{O})$.

\section{Change in Indicators of Quality Communications Due to Hybrid Working}

As shown in the analysis results (see Figure 4), the new model with its 10 indicators fits the data, with the values of the fit indices within acceptable levels. From this, it could be inferred that the corresponding changes that occur when comparing communications quality in HTs and in collocated teams are reflected in these 10 indicators, as illustrated in Figure 5.

As shown in Figure 5, completeness is the indicator most affected with regard to change in the quality of communications due to working in HTs (loading=.88), followed by reliability (loading=.84). These results highlight the detrimental impact of hybrid team working which results in incomplete and unreliable communications. As emphasised by investigators such as Thomas et al. (1998) and Xie et al. (2010), in the construction context, completeness is one of the most important indicators for the quality of communications. The justification could be the limitations and the reduction in the richness of computer-aided communications in the construction environment (Wang et al., 2014). As argued by Dossick et al. (2015), completeness of communications in hybrid construction teams is negatively affected as virtual technology affordances lack alignment with the communication needs of these teams. According to Peñarroja, Orengo, Zornoza and Hernandez (2013), when communications are incomplete, this increases the receiver's uncertainty with their consequent view that the information is less reliable. It is also noticed that the $R^{2}$ values of these two indicators are 0.71 and 0.77 , respectively (see Table 3 ). Thus, approximately $71 \%$ and $77 \%$ of the variance in completeness and reliability of communications, respectively, are explained by changes in the quality of communications, denoting strong relationships between these indicators and these changes.

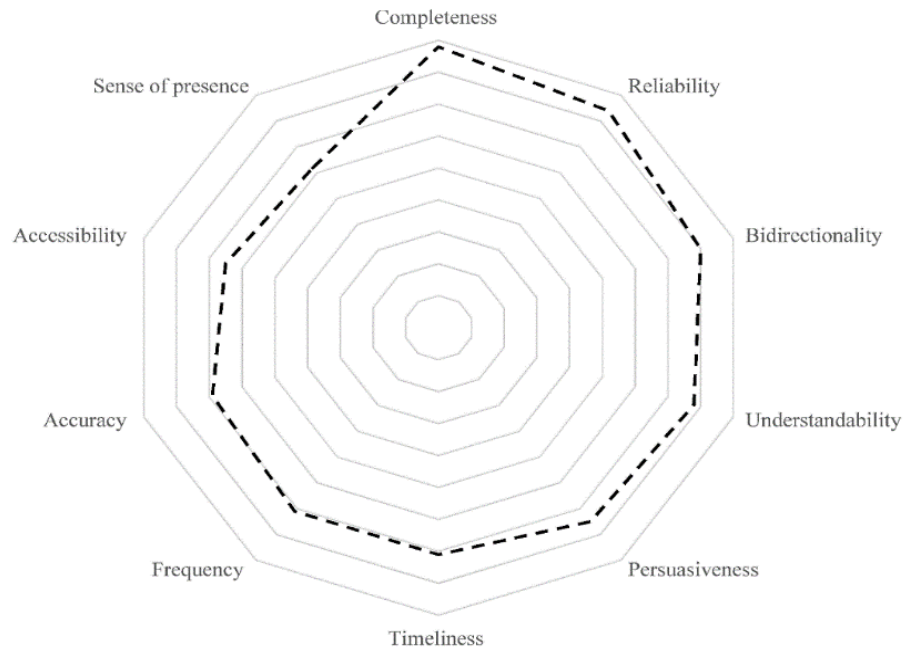

Figure 5. Relative Change in Indicators of Quality of Communications in Hybrid Teams

\section{Conclusion}

Maintaining the quality of communications in construction projects is an urgent need. Westin and Sein (2014) recommended that the first step towards high quality communications involves establishing the criteria and indices so quality can be evaluated, with this found to be an underresearched area in the construction context. The present study adds to the existing body of knowledge by synthesising the available knowledge from other disciplines and customising and contextualising the indices within the natural setting of the construction industry. The result was the identification of 12 indicators that could be utilised in the assessment of the quality of communications in construction project teams. While seven of these indicators were mentioned in previous studies, the current study has added five new measures to create a list of 12 indicators.

As the first of its kind, this empirical study within the construction industry has identified the impacts of working in HTs through using indicators for the quality of communications. The study has discussed and clarified the respective importance of each indicator as a feature of the quality of HT communications. This illuminates the major areas to be affected in HTs as they become the future structure of team working in the construction industry.

Given the widespread use of HTs on construction projects, construction managers are in danger of being affected through losing the level of communications quality in these teams. In this context, the findings of the present study have several implications. These include providing an illuminating insight into the major impacts of shifting to hybrid team working on construction projects. Thus, the findings provide guidelines for construction managers by identifying the main areas of concern and discovering the main aspects on which to focus to maintain the quality of communications in construction project teams. As asserted by Weber and Kim (2015), a better understanding of the impacts of hybrid team working variables will enable managers to more effectively implement HTs and new technology.

Despite the contributions, the findings of the present study should be considered in view of the limitations. The study was conducted in Australia with its specific technical 
and socio-economic characteristics. This might affect the generalisability of the results to other countries. Nevertheless, this limitation opens the window for further investigation which could be conducted by replicating the study in other countries and contexts to add validity to the findings of the present study. Moreover, each single indicator of the quality of communications warrants its own focus. Along with remedial solutions to modify the negative impacts, this is suggested as another ground of inquiry in view of the findings of the present study.

\section{References}

Ahuja, V., Yang, J., \& Shankar, R. (2010). Perceptions Affecting ICT Adoption for Building Project Management in the Indian Construction Industry. International Journal of Construction Management, 10(2), 1-18. https://doi.org/10.1080/15623599.2010.10773141

Aubert, B., Hooper, V., \& Schnepel, A. (2013). Revisiting the role of communication quality in ERP project success. American Journal of Business, 28(1), 64-85. https://doi.org/10.1108/19355181311314770

Bazeley, P. (2007). Qualitative data analysis with NVivo. London: SAGE.

Bazeley, P. (2013). Qualitative data analysis: practical strategies. Thousand Oaks, CA: SAGE.

Becerik-Gerber, B., Ku, K., \& Jazizadeh, F. (2012). BIM-Enabled Virtual and Collaborative Construction Engineering and Management. Journal of Professional Issues in Engineering Education and Practice, 1(1), $234-245$. https://doi.org/10.1061/(ASCE)EI.1943-5541.0000098

Blunch, N. J. (2013). Introduction to structural equation modeling using IBM SPSS statistics and AMOS (2nd ed.). London; Thousand Oaks, CA: SAGE Publications. https://doi.org/10.4135/9781526402257

Boritz, J. E. (2005). IS practitioners' views on core concepts of information integrity. International Journal of Accounting Information Systems, 6(4), 260-279. https://doi.org/10.1016/j.accinf.2005.07.001

Bosch-Sijtsema, P. M., \& Henriksson, L.-H. (2014). Managing projects with distributed and embedded knowledge through interactions. International Journal of Project Management, 32(8), 1432-1444. https://doi.org/10.1016 /j.ijproman.2014.02.005

Brown, T. A. (2006). Confirmatory factor analysis for applied research. New York: Guilford Press.

Byrne, B. M. (2001). Structural equation modeling with AMOS: basic concepts, applications, and programming. Mahwah, NJ: Lawrence Erlbaum Associates.

Ceric, A. (2014). Minimizing communication risk in construction: a Delphi study of the key role of project managers. Journal of Civil Engineering and Management, 20(6), 829-838. https://doi.org/10.3846/13923730.2013.802739

Chen, C., \& Messner, J. I. (2010). A Recommended Practices System for a Global Virtual Engineering Team. Architectural Engineering and Design Management, 6(3), 207-221. https://doi.org/10.3763/aedm.2010.0121

Cheng, E. W. L., Li, H., Love, P. E. D., \& Irani, Z. (2001). Network communication in the construction industry. Corporate Communications: An International Journal, 6(2), 61-70. https://doi.org/10.1108/13563280110390314

Cheung, S. O., Yiu, T. W., \& Lam, M. C. (2013). Interweaving Trust and Communication with Project Performance. Journal of Construction Engineering and Management, 139(8), 941-950. https://doi.org/10.1061/(ASCE)CO.19437862.0000681

Chinowsky, P. S., \& Rojas, E. M. (2003). Virtual teams: Guide to successful implementation. Journal of Management in Engineering, 19(3), 98-106. https://doi.org/10.1061/(ASCE)0742-597X(2003)19:3(98)

Creswell, J. W. (2009). Research design: qualitative, quantitative, and mixed methods approaches (3rd ed.). Thousand Oaks, CA: Sage Publications.

Creswell, J. W., Plano Clark, V. L., Gutmann, M. L., \& Hanson, W. E. (2003). Advanced Mixed Methods Research Designs. In A. Tashakkori \& C. Teddlie (Eds.), Handbook on mixed methods in the behavioral and social sciences. Thousand Oaks, CA: Sage.

Dainty, A., Moore, D., \& Murray, M. (2005). Communication in construction: theory and practice. New York, NY: Taylor \& Francis.

den Otter, A., \& Emmitt, S. (2007). Exploring effectiveness of team communication: Balancing synchronous and asynchronous communication in design teams. Engineering, Construction and Architectural Management, 14(5), 408-419. https://doi.org/10.1108/09699980710780728 
M. Reza Hosseini, Edmundas Kazimieras Zavadskas , Bo Xia, Nicholas Chileshe, Anthony Mills. Communications in...

Dossick, C., Anderson, A., Azari, R., Iorio, J., Neff, G., \& Taylor, J. (2015). Messy Talk in Virtual Teams: Achieving Knowledge Synthesis through Shared Visualizations. Journal of Management in Engineering, 31(1), A4014003. https://doi.org/10.1061/(ASCE)ME.1943-5479.0000301

Ellwart, T., Happ, C., Gurtner, A., \& Rack, O. (2015). Managing information overload in virtual teams: Effects of a structured online team adaptation on cognition and performance. European Journal of Work and Organizational Psychology, 24(5), 812-826. https://doi.org/10.1080/1359432X.2014.1000873

Gabrielaitis, L., \& Bausys, R. (2009). Management of Project Properties in "Virtual Archive" for Building Design Industry. Inzinerine Ekonomika-Engineering Economics(4), 15-23.

Gopsill, J. A., McAlpine, H. C., \& Hicks, B. J. (2013). A Social Media framework to support Engineering Design Communication. Advanced Engineering Informatics, 27(4), 580-597. https://doi.org/10.1016/j.aei.2013.07.002

Griffith, T. L., Sawyer, J. E., \& Neale, M. A. (2003). Virtualness and Knowledge in Teams: Managing the Love Triangle of Organizations, Individuals, and Information Technology. MIS Quarterly, 27(2), 265-287.

Harrington, D. (2009). Confirmatory factor analysis. New York, NY: Oxford University Press.

Hartley, P., \& Bruckham, C. (2000). Business Communication: An Introduction. Florence, KY, USA: Routledge.

Hooper, D., Coughlan, J., \& Mullen, M. (2008). Structural equation modelling: Guidelines for determining model fit. Electronic Journal of Business Research Methods, 6(1), 53-60.

Hosseini, M. R., Chileshe, N., Zuo, J., \& Baroudi, B. (2015). Adopting global virtual engineering teams in AEC projects: A qualitative meta-analysis of innovation diffusion studies. Construction Innovation, 15(2), $151-179$. https://doi.org/10.1108/CI-12-2013-0058

Hosseini, M. R., Zuo, J., Chileshe, N., \& Baroudi, B. (2015). Evaluating virtuality in teams: a conceptual model. Technology Analysis \& Strategic Management, 27(4), 385-404. https://doi.org/10.1080/09537325.2014.1003206

Hyde, K. F. (2000). Recognising deductive processes in qualitative research. Qualitative Market Research: An International Journal, 3(2), 82-90. https://doi.org/10.1108/13522750010322089

Iorio, J., \& Taylor, J. E. (2014). Boundary object efficacy: The mediating role of boundary objects on task conflict in global virtual project networks. International Journal of Project Management, 32(1), 7-17. https://doi.org/10. 1016/j.ijproman.2013.04.001

Kahn, B. K., Strong, D. M., \& Wang, R. Y. (2002). Information quality benchmarks: product and service performance. Communications of the ACM, 45(4), 184-192. https://doi.org/10.1145/505248.506007

Ke, H., Cui, Z., Govindan, K., \& Zavadskas, E. K. (2015). The Impact of Contractual Governance and Trust on EPC projects in Construction Supply Chain Performance. Inzinerine Ekonomika-Engineering Economics, 26(4), 349-363. https://doi.org/10.5755/j01.ee.26.4.9843

Kline, R. B. (2011). Principles and practice of structural equation modeling (3rd ed.). New York, NY: The Guilford Press.

Lewins, A., \& Silver, C. (2007). Using software in qualitative research. London, England: SAGE Publications. https://doi.org/10.4135/9780857025012

Martin, H., Lewis, T. M., \& Fifi, J. (2014). Centralized versus decentralized construction project structure - Easing communication difficulties. International Journal of Construction Management, 14(3), 156-170. https://doi.org/10.1080/15623599.2014.922726

Miller, H. (2005). Information quality and market share in electronic commerce. Journal of Services Marketing, 19(2), 93102. https://doi.org/10.1108/08876040510591402

Mithas, S., Ramasubbu, N., \& Sambamurthy, V. (2011). How information management capability influences firm performance. MIS Quarterly, 35(1), 237-256.

Mohr, J. J., \& Sohi, R. S. (1996). Communication flows in distribution channels: impact on assessments of communication quality and satisfaction. Journal of Retailing, 71(4), 393-415. https://doi.org/10.1016/0022-4359(95)90020-9

Moum, A. (2010). Design team stories: Exploring interdisciplinary use of 3D object models in practice. Automation in Construction, 19(5), 554-569. https://doi.org/10.1016/j.autcon.2009.11.007

Onwuegbuzie, A. J., Dickinson, W. B., Leech, N. L., \& Zoran, A. G. (2009). A qualitative framework for collecting and analyzing data in focus group research. International Journal of Qualitative Methods, 8(3), 1-21. https://doi.org/10.1177/160940690900800301 
Pe-arroja, V., Orengo, V., Zornoza, A., \& Hernandez, A. (2013). The effects of virtuality level on task-related collaborative behaviors: The mediating role of team trust. Computers in Human Behavior, 29(3), 967-974. https://doi.org/10. 1016/j.chb.2012.12.020

Punch, K. F. (2005). Introduction to social research: Quantitative and qualitative approaches. Thousand Oaks, CA: Sage Publications Ltd.

Ramalingam, S., Lobo, S., Mahalingam, A., \& Whyte, J. (2014). Achieving reliability in transnational work on complex projects: new directions for research. Engineering Project Organization Journal, 4(4), 193-208. https://doi.org/10. $1080 / 21573727.2014 .947269$

Rivard, H. (2000). A survey on the impact of information technology on the Canadian architecture, engineering and construction industry. Electronic Journal of Information Technology in Construction, 5, 37-56.

Schreiber, J. B., Nora, A., Stage, F. K., Barlow, E. A., \& King, J. (2006). Reporting structural equation modeling and confirmatory factor analysis results: A review. The Journal of Educational Research, 99(6), 323-338. https://doi.org/10.3200/JOER.99.6.323-338

Schroeder, K. A. (2013). A Mixed Method Study of the Accelerators and Decelerators of Global Hybrid Team Effectiveness. (PhD thesis), Benedictine University.

Senaratne, S., \& Ruwanpura, M. (2016). Communication in construction: a management perspective through case studies in Sri Lanka. Architectural Engineering and Design Management, 12(1), 3-18. https://doi.org/10.1080 /17452007.2015.1056721

Thomas, S., Tucker, R., \& Kelly, W. (1998). Critical Communications Variables. Journal of Construction Engineering and Management, 124(1), 58-66. https://doi.org/10.1061/(ASCE)0733-9364(1998)124:1(58)

Tourish, D., \& Hargie, O. (2009). Communication and organizational sucess. In O. Hargie \& D. Tourish (Eds.), Auditing Organizational Communication: A Handbook of Research, Theory and Practice. Florence, KY, USA: Routledge.

Verburg, R. M., Bosch-Sijtsema, P., \& Vartiainen, M. (2013). Getting it done: Critical success factors for project managers in virtual work settings. International Journal of Project Management, 31(1), 68-79. https://doi.org/10. 1016/j.ijproman.2012.04.005

Vladuțescu, Ș. (2014). Convictive Communication and Persuasive Communication. International Letters of Social and Humanistic Sciences, 15(2), 164-170. https://doi.org/10.18052/www.scipress.com/ILSHS.26.164

Wang, X., Love, P. E. D., Kim, M. J., \& Wang, W. (2014). Mutual awareness in collaborative design: An Augmented Reality integrated telepresence system. Computers in Industry, 65(2), 314-324. https://doi.org/10.1016/ j.compind.2013.11.012

Watson-Manheim, M. B., Chudoba, K. M., \& Crowston, K. (2012). Perceived discontinuities and constructed continuities in virtual work. Information Systems Journal, 22(1), 29-52. https://doi.org/10.1111/j.1365-2575.2011.00371.x

Weber, M. S., \& Kim, H. (2015). Virtuality, Technology Use, and Engagement Within Organizations. Journal of Applied Communication Research, 43(4), 385-407. https://doi.org/10.1080/00909882.2015.1083604

Westin, S., \& Sein, M. K. (2014). Improving Data Quality in Construction Engineering Projects: An Action Design Research Approach. Journal of Management in Engineering, 30(3), 05014003. https://doi.org/10.1061/(ASCE) ME.1943-5479.0000202

Xie, C., Wu, D., Luo, J., \& Hu, X. (2010). A case study of multi-team communications in construction design under supply chain partnering. Supply Chain Management: An International Journal, 15(5), 363-370. https://doi.org/10. $1108 / 13598541011068279$

Xiong, B., Skitmore, M., \& Xia, B. (2015). A critical review of structural equation modeling applications in construction research. Automation in Construction, 49, Part A, 59-70. https://doi.org/10.1016/j.autcon.2014.09.006

Xu, H., Nord, J. H., Nord, G. D., \& Lin, B. (2003). Key issues of accounting information quality management: Australian case studies. Industrial Management \& Data Systems, 103(7), 461-470. https://doi.org/10.1108/ 02635570310489160

Zavadskas, E. K., Turskis, Z., \& Tamosaitiene, J. (2010). Risk assessment of construction projects. Journal of Civil Engineering and Management, 16(1), 33-46. https://doi.org/10.3846/jcem.2010.03

The article has been reviewed.

Received in December, 2015; accepted in June, 2017. 